I6 a 18 de autubro de 2019 - Campinas | Brasil

\title{
ABORDAGENS EM LINGUAGEM ADOTADAS POR FONOAUDIÓLOGOS NO SISTEMA PÚBLICO DE SAÚDE EM CAMPINAS E AMERICANA
}

\section{Antonio Lucas Gonçalves Rodrigues*, Irani Rodrigues Maldonade}

\section{Resumo}

Este trabalho está inserido nas ações de Saúde Coletiva em Fonoaudiologia e tem como objetivo investigar, entre os fonoaudiólogos que atuam no setor público da saúde em Campinas e Americana, qual é a abordagem teórica em linguagem com que se identificam e adotam suas práticas. Para isso, foram entrevistadas cerca de dez fonoaudiólogas com vistas a verificar se tais profissionais identificam bases teóricas para sua atuação em linguagem e se conseguem estabelecer diferenças entre os modos de atuação. As entrevistas, registradas em áudio, foram transcritas e analisadas por meio do estabelecimento de categoriais, aferidas pelos pesquisadores, com base em critérios como relevância. Os resultados indicam que as profissionais reconhecem bases teóricas para atuação em linguagem, mas demonstram dificuldades em diferenciar correntes. Além disso, a maior parte das respondentes referiu mesclar as abordagens teóricas na clínica, o que pode sugerir distanciamento entre componentes clínicos e teóricos da Fonoaudiologia bem como distanciamentos entre Fonoaudiologia e Linguística. Os achados reforçam a necessidade de (re)aproximação entre os componentes clínicos e teóricos da Fonoaudiologia bem como a necessidade de realização de estudos envolvendo a dimensão terapêutica em Linguagem e Fonoaudiologia.

Palavras-chave: clínica fonoaudiológica, linguagem, saúde coletiva.

\section{Introdução}

Em qualquer que seja seu nível de inserção na atenção à saúde o fonoaudiólogo lidará com questões que se relacionam direta ou indiretamente com a linguagem e não apenas com a comunicação. Nosso interesse pelo tema está relacionado ao fato de que as alterações de fala e linguagem são a maior demanda fonoaudiológica no SUS ${ }^{1-4}$ e que as investigações em linguagem, principalmente no que concerne à sua aquisição, patologias e terapia, não foram exauridas. Em função das diferentes correntes teóricas que permeiam a Fonoaudiologia (figura 1), questionamo-nos sobre o que faz o fonoaudiólogo clínico diante das diferentes possibilidades do trabalho com a linguagem e com o sujeito. Por essa razão, este trabalho tem como objetivo investigar, entre os fonoaudiólogos que atuam no setor público da saúde em Campinas e Americana, qual é a abordagem teórica em linguagem com que se identificam e adotam suas práticas. Para isso, realizamos entrevistas semiestruturadas com fonoaudiólogas e transcrevemos tais entrevistas destacando trechos aferidos como relevantes.
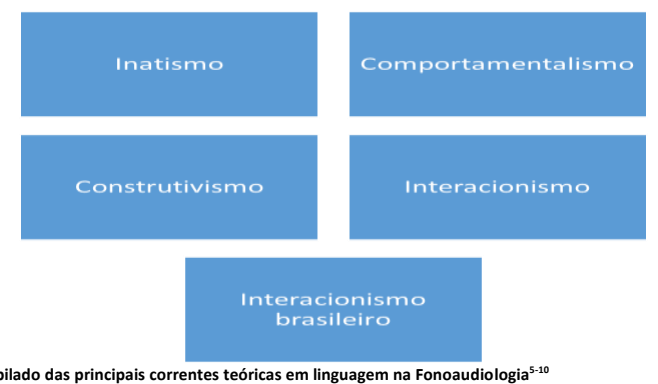

\section{Resultados e Discussão}

Participaram do estudo 10 fonoaudiólogas, sendo 4 do sistema de saúde de Campinas e 6 do sistema de saúde de Americana. O menor tempo de trabalho com linguagem foi 3 anos e o maior foi 30 anos. De modo geral, as profissionais demonstram inclinações ao interacionismo de Vygotsky (3), ao interacionismo brasileiro (2), à abordagem pragmática (1) e à neurolinguística discursiva (4). A maior parte das respondentes referiu mesclar as abordagens teóricas na clínica. Nossas hipóteses quanto à mesclagem teórica apontam para a) pouca aproximação da Fonoaudiologia à
Linguística ${ }^{11,12}$ e, consequentemente, b) necessidades de fonoaudiólogos aprofundarem os estudos em linguagem e c) distanciamento teórico e clínico na Fonoaudiologia.

S3: Então as minhas terapias dentro do CAPS eu foco muito na linguagem, na interação, na brincadeira. No jogo, né? E aí eu uso a brincadeira e o lúdico que daí extravasa, que não é nosso, de novo, né, que a gente vai pra uma outra área. Nem tanto Piaget, né? Porque Piaget fala que cê tem que deixar a criança descobrir o mundo, né? E aí eu vou mais pro Vygostky porque fala que não é a criança só descobrir o mundo. Você também tem que apresentar o mundo pra essa criança. E a própria De Lemos fala que a aquisição se dá com o outro e na interação com o outro, né? Que
essa criança é envolta pela linguagem. É laçada pela linguagem, né? Então, né, nas brincadeiras eu faço isso e aí é essa criança e envolta pela linguagem. Elaçada pela linguagem, ne? Entáo, ne, nas brincadeiras eu faço isso e aí
brincadeira... Do comportamentalismo, tá, vamos lá. Behaviorismo. Acho que a gente consegue vê. Acho que é brincadeira... Do comportamentalismo, tá, vamos lá, Behaviorismo. Acho que a gente consegue vê. Acho que é
importante. Não é algo que eu estude. É algo que a gente teve também na graduação lá no primeiro ano, se não me engano.

S1: Olha, sendo bem sincera com você, eu faço um pouco de tudo, né? Mas foi a partir das transcrições que eu fiz no mestrado que eu percebi isso. É, mas a gente é... como atuação clínica cê vai perceber que a gente vai fazendo tentativas. Então assim, por mais que você saiba que isso cientificamente não é bom, mas você acaba têm outros tipos de formação e normalmente a gente faz uma salada, mesmo. Por isso que é bom a gente sempre

\section{Conclusões}

Nossos achados reforçam a necessidade de (re)aproximação entre os componentes clínicos e teóricos da Fonoaudiologia. Além disso, ressaltamos a necessidade de realização de estudos envolvendo a dimensão terapêutica em Linguagem e Fonoaudiologia.

\section{Agradecimentos}

Agradecemos ao CNPq pelo financiamento e os serviços de saúde de Campinas e americana por permitirem as entrevistas.

1. César AM, Maksud SS. Caracterizaça da demanda de fonoaudiologia no servico público municipal de Ribeirão da Neves-MG. Revista CEFAC. 2007; 9(1):133-8.

2. Da costa RG, De Souza LBR. Perfil dos usuários e da demanda pelo serviço da clínica escola de fonoaudiologia da UFBA. Revista de Ciências Médicas e Biológicas. 2009;8(1): 53-9.

3. Diniz RD, Bordin R. Demanda em Fonoaudiologia em um serviço público municipal da região Sul do Brasil. Revista da Sociedade Brasileira de Fonoaudiologia. São Paulo. 2011;16(2): 126131 ;

4. Donadon C, Bittencourt ZZLC. ESTUDO DA DEMANDA ACOLHIDA EM UMA CLÍNICAESCOLA DE FONOAUDIOLOGIA.

5. Palladino RRR, Machado FP. Aquisição de Linguagem e Fonoaudiologia - Três Questões em Pauta. In: Marchesan IQ, Silva HJ, TOMÉ MC (orgs). Tratado de especialidades em Fonoaudiologia. Rio de Janeiro, RJ: Roca, 2014, p. 1060-6.

5. De quadros RM. O paradigma gerativista e a aquisição da linguagem. In: De quadros RM, Finger I. Teorias de aquisição da linguagem. Ed. da UFSC, 2008, p. 25-48.

6. FINGER, I. A aquisição da linguagem na perspectiva behaviorista. IN: QUADROS, R. M. de. Teorias de aquisição da linguagem. Florianópolis, SC: Editora da UFSC, 2008, p. 8-24.

7. Ramozzi-chiarottino Z. Epistemologia genética e a aquisição da linguagem. IN: Quadros RM, Finger I. Teorias de aquisição da linguagem. Florianópolis, SC: Editora da UFSC, p. 83114, 2008. 8. De lemos CTG. Los processos metafóricos y metonímicos como mecanismo de cambio. Substractum. 1992;1(1): 120-30.

9. De lemos CTG. Das Vicissitudes da fala da criança e de sua investigação. Cadernos de Estudos Linguísticos. Campinas. 2002; 42(1): 41-69.

10. Maldonade IR. A (in) flexibilidade pragmática na fala da criança e os erros no processo de aquisição da linguagem. Estudos Linguísticos. São Paulo. 2018;47(2): 306-318.

11. Lier-de vitto MF. Patologias da linguagem: subversão posta em ato. In Nina Leite (Org.) Corpolinguagem: Gestos e afetos. Campinas: Mercado de Letras, 2003, p. 25-32.

12. Lier-de vitto MF. Patologias da linguagem: sobre as "vicissitudes de falas sintomáticas".
. 12. Lier-de vitto MF. Patologias da linguagem: sobre as
Aquisição, patologias e clínica de linguagem, p. 47-60, 2006. 